\title{
Molar Pregnancy: Genetic, Histological, Clinical Features and the Risk for Gestational Trophoblastic Neoplasia
}

\author{
Sue Yazaki Sun ${ }^{1}$, Marcia Marcelino de Souza Ishigai ${ }^{2}$, Rosana Mercante Martinez ${ }^{3}$, Maria Teresa de Seixas \\ Alves $^{2}$ and Andréa Cristina de Moraes Malinverni ${ }^{2,3 *}$ \\ ${ }^{1}$ Department of Obstetrics, Universidade Federal de São Paulo - UNIFESP, Brazil
}

${ }^{2}$ Department of Pathology, Universidade Federal de São Paulo - UNIFESP, Brazil

${ }^{3}$ Laboratory of Molecular Pathology, Universidade Federal de São Paulo - UNIFESP, Brazil

Submission: March 11, 2017; Published: March 27, 2017

*Corresponding author: Andréa Cristina de Moraes Malinverni, Laboratory of Molecular Pathology, Department of Pathology, Universidade Federal de São Paulo - UNIFESP, Pedro de Toledo, 781, 5a andar, Vila Clementino, CEP: 04039-032, São Paulo, SP, Brazil, Tel: 5511-5576-4848;

Email: andreamoraesmalinverni@gmail.com

\section{Abstract}

Hydatidiform mole (HM) is a complication of pregnancy, genetically abnormal, characterized by several degrees of trophoblastic proliferation and hydropic degeneration of chorionic villi with potential for malignant transformation. The HM is classified as complete hydatidiform mole (CHM) and partial hydatiform mole (PHM). The distinction between CHM and PHM and non-molar abortions (NM) is very important since the risk for the development of postmolar gestational trophoblastic neoplasia is higher in CHM. This article is a brief review of relevant topics about genetic, histological and clinical features of molar pregnancy.

Keywords: Molar pregnancy; Hydatidiform mole; Partial hydatidform mole; Complete hydatidform mole; Gestational trophoblastic neoplasia

\section{Introduction}

Molar pregnancy represents an obstetric complication of the first half of gestation in which the abnormal developmental of the placenta is characterized by excessive villous edema and the proliferation of the trophoblast [1]. The excessive villous stromal edema culminates with central cisterns formation, visible at macroscopic and ultrasonographic examination. Based on the morphological, genetic and clinical aspects, HM can be classified as complete (CHM) or partial (PHM) hydatidiform mole [1,2].

The CHM presents hydropic chorionic villi, trophoblastic hyperplasia and high levels of human chorionic gonadotropin hormone ( $\beta$-hCG) [3]. However, in the PHM the placenta has normal and hydropic villi with the presence of fetal or embryonic elements, trophoblastic hyperplasia with pseudoinclusions, dual villous populations and lower levels of chorionic gonadotrophin $[1,4]$.

HM is considered the most frequent form of gestational trophoblastic dIsease (GTD), with estimated global incidence of 1 to 3 per 1000 pregnancies. The incidence in Asian countries and Latin America is higher than that reported in Europe and
North America. In Brazil there is no specific official record and it is estimated to occur in 1: 200-400 pregnancies, but this rate is based on data from reference centers for GTD which is quite high and probably does not reflect the population as a whole [5-7]. The risk for gestational trophoblastic neoplasia after the patient has had a CHM was observed in $10-30 \%$ and rarely occurs after PHM (0.5-5\%) $[1,5,8]$.

The distinction between CHM and PHM is very important because in CHM there is higher risk of progression of developing gestational trophoblastic neoplasia. Some cases of PHM have abnormal villous morphology that can be confused with NM. The clinical investigations and immunostaining with molecular studies are important to distinguish the diagnosis of PHM and NM.

\section{Genetic aspects of hydatidiform mole}

In the 70's some molecular investigations established the genetic bases of hydatidiform [9]. Genetically, CHM is diploid and $80 \%$ has 46XX karyotype in which all chromosomes are of paternal origin. This is because an enucleated egg without maternal genes 
was fertilized by a haploid sperm (monospermia) followed by duplication forming a homozygous egg 46,XX. In the remaining $20 \%$ of CHM, the karyotype is 46 , XY, due to the fertilization of an anucleated egg by two haploid sperm (dyspermia). In both cases we can say that CHM karyotype is androgenetic diploid $[1,8,10]$.

Sometimes CHM can be related to mutations in the gene NLRP7 with an increase the risk to recurrent hydatidiform mole [11]. In the first-trimester miscarriages, Triplody is one of the most common chromosome abnormalities present in $18 \%$ of first-trimester miscarrisges. $[12,13]$. The mechanism of genetic formation of the triploidy may result from fertilization of a normal haploid egg by two normal sperm or fertilization of a haploid egg by a diploid sperm. Another possibilite is a fertilization of a diploid egg by normal haploid sperm. This is also true for PHM, which $70 \%$ of the cases has 69 , XXY karyotype, but this finding can be different: $69, \mathrm{XXX}$ or $69, \mathrm{XYY}$. The PHM has a maternal haploid component and two paternal (diandrica triploidy) which differs genetically from non-molar triploidy $[1,8,14]$.

Several genetic methodologies aid to improve the diagnosis of HM. The conventional karyotyping is the most used technique to identify the numerical and structural chromosomal abnormalities and confirms the presence of triploidy in HPM and diploidy in CHM. However, it cannot be used with formalinfixed paraffin-embedded or alcohol tissues, only in fresh samples $[12,13,15]$. Flow cytometry is a method for analyzing ploidy in fresh and paraffin-embedded samples. It only allows the detection of polyploidy (triploidy) and does not detect trisomy and monosomy. Thus it separates a PHM from a CHM, but cannot distinguish between non-molar digynic triploid gestations and PHM [16-18]. Fluorescence in situ hybridization (FISH) is an indispensable technique in the study of the physical mapping of human genome because it allows a precise regional chromosomal location of single copy genes or repeated sequences of DNA. It can be used in paraffin-embedded samples, analyzes the ploidy and identifies the most common chromosomal abnormalities related to NM abortions according to the probes were used $[12,19]$. Molecular genotyping of microsatellites has been widely used in distinguishing HM. This technique can be performed with DNA from fresh or paraffin- embedded samples, allows analyzing alterations for ploidy and the parental origin of the genetic components present in the sample [20-23]. Each of these methods has their particularities, advantages and disadvantages $[21,22,24,25]$.

\section{Histological characteristics of HM}

The diagnosis of HM is based on its morphology. In classical cases, around the 2 nd trimester, the abnormally large villi have a vesicular or a grape-like appearance. Histologically, HM presents variable degrees of circumferential trophoblastic hyperplasia and epithelial atypia. Usually they are more pronounced on CHM. PHM displays irregular villous contours with geographic appearance becoming frequent epithelial pseudoinclusions into the villous stroma. Different from CHM, a compound of a mixture of normal and abnormal villi, less number of vesicles and prominent stromal fibrosis. Cellular debris (stromal and vascular karyorrhexis) occurs in both types of HM, mainly in CHM [26]. The presence of membranes, fetal tissues or nucleated RBCs is uncommon in CHM unless it is twin pregnancy. This typical morphological pattern has changed over the years due to molar evacuation in early gestational age before the 11 th week. $[26,27]$. At this stage the vesicles are less visible at macroscopy and cisterns are rare on histological examination. In early CHMs the villi has a typical "budding" arrangment, myxoid basophilic stroma with or without a collapsed vascular network. Some cases can be confused with non-molar abortion on pathology and US examination [28]. The p57 gene search by immunohistochemistry, allows for distinguishing CHM from PHM and non-molar abortions as the gene CDKN1C is maternally expressed and therefore, can be detected only in sample with maternal DNA. As expected, CHM is negative for p57 while non-molar and PHM present positivity in villous stroma and cytotrophoblast cells [29].

\section{Clinical features of patients}

The clinical features of CHM and PHM depend on the gestational age of diagnosis. Currently, due to an early detection of failed pregnancy by ultrasonography scan associated to high level of human chorionic gonadotropin the mean in the mean gestational age at diagnosis of HM has been decreasing. CHM has been diagnosed at 9 weeks and PHM at 12 weeks [6]. It contributes to a milder clinical presentation of $\mathrm{HM}$ resembling to miscarriage. Vaginal bleeding remains as the most common clinical feature occurring in $42 \%$ of cases of CHM and in $15 \%$ of cases of PHM [6]. Only $27.3 \%$ of PHM cases are diagnosed previously to evacuation and the diagnosis is made by the histhopatological exam. Classical symptoms of HM as hyperemesis, preeclampsia, hyperthyroidism and theca-lutein cyst as well as respiratory distress are becoming less common. However, early diagnosis of CHM did not reduce the progression to gestational trophoblastic neoplasia [27]. Similar results were reported in Brazil [30].

\section{Risk of gestational trophoblastic neoplasia}

After the molar evacuation is recommended a weekly hCG measurement until three negatives values and after that, 6 monthly negative values in cases of CHM [31]. Some investigators have shortened the surveillance in cases of PHM to 2 negative values $(<5 \mathrm{mIU} / \mathrm{mL})$. Besides the hCG surveillance it is important the use of an effective contraceptive method. The diagnosis of GTN is based on the FIGO 2000 criteria:

a. Weekly hCG plateauing for at least 4 consecutive measurements for a period of at least 3 weeks (days $0,7,14,21)$,

b. Weekly hCG rising for at least 3 consecutive measurements for a period of least 2 weeks (days $0,7,14$ )

c. Persistence of hCG more than 6 months after evacuation, 
d. $95 \%$ of postmolar GTN are classified as low risk GTN (I to III, score 0-6) and the treatment is made with single chemotherapy agent, methotrexate or actinomicin D, reaching almost $100 \%$ of cure. High risk postmolar GTN (IV, score $>7$ ) is treated with EMA-CO and the survival in 5 years is of $8.2 \%$ [32-33].

\section{Conclusion}

CHM and PHM have been diagnosed in the first trimester of pregnancy resulting in a further decrease in some clinical classical presenting symptoms. The risk of development of post molar GTN has not been affected. After molar evacuation, the HM is usually classified based on morphological criteria and the use of immunohistochemical and molecular methods have improved the understanding of molar pregnancies. Further research about oncogenes and other immunomodulator molecules are important as prognostic markers.

\section{Conflict of Interest}

All contributors approved the submission to the Journal, and there is no conflict of interests.

\section{References}

1. Seckl MJ, Sebire NJ, Fisher RA, Golfier F, Massuger L, et al. (2013) Gestational trophoblasticdisease: ESMO Clinical Practice Guidelines for diagnosis, treatment and follow-up. Ann Oncol 24(Suppl 6): vi39-50.

2. Szulman AE, Surti U (1978) The syndromes of hydatidiform mole. I. Cytogenetic and morphologic correlations. Am J Obstet Gynecol 131(6): 665-671.

3. Lurain JR (2010) Gestational trophoblastic disease I: epidemiology, pathology, clinical presentation and diagnosis of gestational trophoblastic disease, and management of hydatidiform mole. Am J Obstet Gynecol 203(6): 531-539.

4. Howat AJ, Beck S, Fox H, Harris SC, Hill AS, et al. (1993) Can histopathologists reliably diagnose molar pregnancy? J Clin Pathol 46(7): 599-602.

5. Sebire NJ, Seckl MJ (2008) Gestational trophoblastic disease: current management of hydatidiform mole. BMJ 337: a1193.

6. Sun SY, Melamed A, Joseph NT, Gockley AA, Goldstein DP, et al. (2016) Clinical Presentation of Complete Hydatidiform Mole and Partial Hydatidiform Mole at a Regional Trophoblastic Disease Center in the United States Over the Past 2 Decades. Int J Gynecol Cancer 26(2):36770 .

7. Ferraz L, Lopes PdF, Amim-Junior J, Montenegro CAB, Braga A (2015) Atualização no diagnóstico e tratamento da gravidez molar. Jornal Brasileiro de Medicina 103(2): 6.

8. Merchant SH, Amin MB, Viswanatha DS, Malhotra RK, Moehlenkamp C, et al. (2005) p57KIP2 immunohistochemistry in early molar pregnancies: emphasis on its complementary role in the differential diagnosis of hydropic abortuses. Hum Pathol 36(2): 180-186.

9. Kajii T, Ohama K (1997) Androgenetic origin of hydatidiform mole. Nature 268(5621): 633-634.

10. de Andrade JM (2009) Hydatidiform mole and gestational trophoblastic disease. Rev Bras Ginecol Obstet 31(2): 94-101.

11. Dixon PH, Trongwongsa P, Abu-Hayyah S, Ng SH, Akbar SA, et al. (2012) Mutations in NLRP7 are associated with diploid biparental hydatidiform moles, but not androgenetic complete moles. J Med Genet 49(3): 206-211.
12. Moraes AC, Moron AF, Hashimoto E, Silva IDG, Torloni MR, et al. (2005) Abordagem citogenética e molecular em abortos espontâneos. Rev Bras Ginecol Obstet 27(9): 7.

13. Proite MM, Malinverni AM, Oshima CT, Ishigai MM, Moron AF et al. (2016) Mutations in the Gene for Factor V Leiden and G20210A Prothrombin Polymorphism in Women With Recurrent Spontaneous Abortion: A Retrospective Study in a Brazilian Population. J Clin Gynecol Obstet 5(3): 85-91.

14. Lewis GH, Scipio DC, Murphy KM, Haley L, Beierl K, et al. (2013) Characterization of androgenetic/biparental mosaic/chimeric conceptions, including those with a molar component: morphology, p57 immnohistochemistry, molecular genotyping, and risk of persistent gestational trophoblastic disease. Int J Gynecol Pathol 32(2): 199-214.

15. Buza N, Hui P (2014) Immunohistochemistry and other ancillary techniques in the diagnosis of gestational trophoblastic diseases. Semin Diagn Pathol 31(3): 223-232.

16. Fisher RA, Lawler SD, Ormerod MG, Imrie PR, Povey S (1987) Flow cytometry used to distinguish between complete and partial hydatidiform moles. Placenta 8(3): 249-256.

17. Fukunaga M (2001) Flow cytometric and clinicopathologic study of complete hydatidiform moles with special reference to the significance of cytometric aneuploidy. Gynecol Oncol 81(1): 67-70.

18. Paradinas FJ, Browne P, Fisher RA, Foskett M, Bagshawe KD, et al. (1996) A clinical, histopathological and flow cytometric study of 149 complete moles, 146 partial moles and 107 non-molar hydropic abortions. Histopathology 28(2): 101-110.

19. Hackel C, Varella-Garcia M (1997) Interphase cytogenetics using fluorescence in situ hybridization: an overview of its application to diffuse and solid tissue. Braz J Genet 20(1):10.

20. Murphy KM, McConnell TG, Hafez MJ, Vang R, Ronnett BM (2009) Molecular genotyping of hydatidiform moles: analytic validation of a multiplex short tandem repeat assay. J Mol Diagn 11(6): 598-605.

21. Fisher RA, Tommasi A, Short D, Kaur B, Seckl MJ, et al. (2014) Clinical utility of selective molecular genotyping for diagnosis of partial hydatidiform mole; a retrospective study from a regional trophoblastic disease unit. J Clin Pathol 67(11): 980-984.

22. Sebire NJ, May PC, Kaur B, Seckl MJ, Fisher RA (2016) Abnormal villous morphology mimicking a hydatidiform mole associated with paternal trisomy of chromosomes 3,7,8 and unipaternal disomy of chromosome 11. Diagn Pathol 11: 20.

23. Madi JM, Braga AR, Paganella MP, Litvin IE, Da Ros Wendland EM (2016) Accuracy of p57(KIP2) compared with genotyping for the diagnosis of complete hydatidiform mole: protocol for a systematic review and meta-analysis. Syst Rev 5(1): 169.

24. Kipp BR, Ketterling RP, Oberg TN, Cousin MA, Plagge AM, et al. (2010) Comparison of fluorescence in situ hybridization, p57 immunostaining, flow cytometry, and digital image analysis for diagnosing molar and non-molar products of conception. Am J Clin Pathol 133(2): 196-204.

25. McConnell TG, Murphy KM, Hafez M, Vang R, Ronnett BM (2009) Diagnosis and subclassification of hydatidiform moles using p57 immunohistochemistry and molecular genotyping: validation and prospective analysis in routine and consultation practice settings with development of an algorithmic approach. Am J Surg Pathol 33(6): 805817.

26. Petts G, Fisher RA, Short D, Lindsay I, Seckl MJ, et al. (2014) Histopathological and immunohistochemical features of early hydatidiform mole in relation to subsequent development of persistent gestational trophoblastic disease. J Reprod Med 59: 213-220.

27. Sun SY, Melamed A, Goldstein DP, Bernstein MR, Horowitz NS, et al. (2015) Changing presentation of complete hydatidiform mole at the New England Trophoblastic Disease Center over the past three 
decades: does early diagnosis alter risk for gestational trophoblastic neoplasia? Gynecol Oncol 138(1): 46-49.

28. Sebire NJ, Rees H, Paradinas F, Seckl M, Newlands E (2001) The diagnostic implications of routine ultrasound examination in histologically confirmed early molar pregnancies. Ultrasound Obstet Gynecol 18(6): 662-625.

29. Vang R, Gupta M, Wu LS, Yemelyanova AV, Kurman RJ, et al. (2012) Diagnostic reproducibility of hydatidiform moles: ancillary techniques (p57 immunohistochemistry and molecular genotyping) improve morphologic diagnosis. Am J Surg Pathol 36(3): 443-453.

30. Braga A, Moraes V, Maestá I, Júnior AJ, Rezende-Filho J, et al. (2016) Changing Trends in the Clinical Presentation and Management of Complete Hydatidiform Mole Among Brazilian Women. Int J Gynecol Cancer 26(5): 984-990.
31. Berkowitz RS, Goldstein DP (2009) Clinical practice. Molar pregnancy. N Engl J 360(16): 1639-1645.

32. Ngan HY, Bender H, Benedet JL, Jones H, Montruccoli GC, et al. (2003) Gestational trophoblastic neoplasia, FIGO 2000 staging and classification. Int J Gynaecol Obstet 83(Suppl 1): 175-177.

33. Mangili G, Lorusso D, Brown J, Pfisterer J, Massuger L, et al. (2014) Trophoblastic disease review for diagnosis and management: a joint report from the International Society for the Study of Trophoblastic Disease, European Organisation for the Treatment of Trophoblastic Disease, and the Gynecologic Cancer InterGroup. Int J Gynecol Cancer 24(9 Suppl 3): S109-S116. 